\title{
A STUDY OF PREVALENCE OF HYPOTHYROIDISM IN DIABETIC PATIENTS
}

\author{
Anurag Chaurasia1, Vikramaditya Meena ${ }^{2}$ \\ ${ }^{1}$ Associate Professor, Department of Medicine, SS Medical College, Rewa. \\ 2Junior Resident, Department of Medicine, SS Medical College, Rewa.
}

\section{ABSTRACT}

\section{BACKGROUND}

Diabetes mellitus (DM) and Thyroid dysfunction (TD) are the two most common endocrine disorders in clinical practice. Unrecognised TD may adversely affect the metabolic control and add more risk to an already predisposed scenario for cardiovascular diseases.

The aims and objectives of this study is to estimate the prevalence of hypothyroidism in diabetics and to establish the correlation between the thyroid disorder and diabetes.

\section{MATERIALS AND METHODS}

This was a descriptive study. One hundred and fifty patients either attending OPD or admitted in Department of Medicine, SGMH, Rewa were assessed during Jul 2014 - Sept 2015. The inclusion criteria are known cases of DM. All patients underwent clinical and laboratory evaluation in which blood pressure, waist-hip ratio, BMI, duration of diabetes, fasting plasma glucose, postprandial plasma glucose, HbA1c, thyroid profile and lipid profile were investigated.

\section{RESULTS}

Out of 150 diabetes mellitus patients for the study of which 75 are males and 75 are females, the prevalence of TD in all diabetic patients was 32\% (48 pts.) and 68\% (102 pts.) were euthyroid. Among patients with TD 16\% have subclinical hypothyroidism, $10.67 \%$ have clinical hypothyroidism, $3.33 \%$ have subclinical hyperthyroidism and $2 \%$ have clinical hyperthyroidism. Thyroid dysfunction was more common among females. Elderly population had higher incidence of thyroid dysfunction. Increased duration of diabetes was associated with increased incidence of thyroid dysfunction. Hypothyroid patients had significantly higher BMI (26.78 v/s 24.17) and mean waist hip ratio as compared to euthyroid diabetics. Hyperthyroid patients had poor glycaemic control and hypothyroid patients had more chances of hypoglycaemia.

\section{CONCLUSION}

We conclude that screening for thyroid disease among diabetic patients should be routinely performed considering the prevalence of new cases diagnosed and the possible aggravation of the classical risk factors such as hypertension and dyslipidaemia arising from an undiagnosed thyroid dysfunction. Furthermore, it seems that unidentified thyroid dysfunction could negatively impact diabetes and its complications. Therefore, diagnosis and management of hypothyroidism in patients with diabetes may prove beneficial.

\section{KEYWORDS}

Diabetes Mellitus, Prevalence, Hypothyroidism.

HOW TO CITE THIS ARTICLE: Chaurasia A, Meena V. A study of prevalence of hypothyroidism in diabetic patients. J. Evolution Med. Dent. Sci. 2017;6(67):4805-4809, DOI: 10.14260/Jemds/2017/1042

\section{BACKGROUND}

Diabetes mellitus (DM) refers to a group of common metabolic disorders that share the phenotype of hyperglycaemia. Several distinct types of DM are caused by a complex interaction of genetics and environmental factors. ${ }^{1}$

The prevalence of diabetes for all age groups worldwide was estimated to be $2.8 \%$ in 2000 and $4.4 \%$ in 2030 . The total number of people with diabetes is projected to rise from 171 million in 2000 to 366 million in $2030 .^{2}$

Diabetes mellitus and thyroid diseases are the two common endocrinopathies seen in the adult population. With

Financial or Other, Competing Interest: None.

Submission 27-06-2017, Peer Review 09-08-2017,

Acceptance 16-08-2017, Published 21-08-2017.

Corresponding Author:

Vikramaditya Meena,

S/o. Chiranji Lal Meena,

Village-Soorwal,

District-Sawaimadhopur-322027.

Rajasthan.

E-mail: drvikramaditya1989@gmail.com

DOI: $10.14260 /$ jemds $/ 2017 / 1042$

\section{(c) $(1)$}

insulin and thyroid hormones being intimately involved in cellular metabolism and thus excess or deficit of either of these hormones could result in the functional derangement of the other. ${ }^{3}$ Thyroid disease is common in the general population, and the prevalence increases with age. Hypothyroidism is by far the most common thyroid disorder in the adult population and is more common in older women. It is usually autoimmune in origin, presenting as either primary atrophic hypothyroidism or Hashimoto's thyroiditis. Thyroid failure secondary to radioactive iodine therapy or thyroid surgery is also common. Rarely, pituitary or hypothalamic disorders can result in secondary hypothyroidism. ${ }^{4}$

Diabetic patients have a higher prevalence of thyroid disorders compared with the normal population. Because patients with one organ-specific autoimmune disease are at risk of developing other autoimmune disorders and thyroid disorders are more common in females, it is not surprising that up to $30 \%$ of female type 1 diabetic patients have thyroid disease. The rate of postpartum thyroiditis in diabetic patients is three times that in normal women. A number of reports have also indicated a higher than normal prevalence 
of thyroid disorders in type 2 diabetic patients with hypothyroidism being the most common disorder. ${ }^{4}$

Apart from autoimmune aetiology linked to the higher prevalence of thyroid disease in DM, it has also been observed that thyroid function is intrinsically linked to insulin resistance. It has also been stated that common factors simultaneously are responsible for increased TSH levels and insulin resistance. ${ }^{5}$

Thyroid hormones exert profound effects in the regulation of glucose homeostasis. These effects include modifications of circulating insulin levels and counterregulatory hormones, intestinal absorption of glucose, hepatic production of glucose, uptake of glucose by peripheral tissues. While thyroid hormones oppose the action of insulin and stimulate hepatic gluconeogenesis and glycogenolysis, 6,7 they up-regulate the expression of genes such as glucose transporter-4 and phosphoglycerate kinase involved in glucose transport and glycolysis respectively, thus acting synergistically with insulin in facilitating glucose disposal and utilisation in peripheral tissue. 8,9

In type $2 \mathrm{DM}$ prevalence of thyroid disease has been found to be as high as $31.4 \%$, the most common disorder being subclinical hypothyroidism followed by subclinical hyperthyroidism, overt hypothyroidism and overt hyperthyroidism. ${ }^{10}$

\section{MATERIALS AND METHODS}

This was a descriptive study and undertaken in the Department of Medicine, S. S. Medical College and associated S. G. M. Hospital, Rewa (M. P.) over a period of 15 months from July 2014 to September 2015. The study sample included 150 diabetes mellitus patients $(75$ male and 75 female) presented in the wards and outpatients department. This was a descriptive study. Patients with diabetes mellitus older than 15 years either newly diagnosed or on treatment as per ADA 2014 criteria were included in the study. Those patients with previous thyroid surgery and previously diagnosed non-diabetic hypothyroid patients on treatment were excluded.

Patients were screened to determine their diabetes status, age, sex and addiction. A detailed history was taken and examination done as per the proforma. Written informed consent was taken from all patients. All patients in addition to haematological and routine urine workup underwent clinical and laboratory evaluation in which blood pressure, waist-hip ratio, BMI, duration of diabetes, fasting plasma glucose, postprandial plasma glucose, HbA1c, thyroid profile and lipid profile were investigated. All patients were evaluated for thyroid status by estimation of serum T3, T4 and TSH levels by Chemiluminescence assay method. A $2 \mathrm{~mL}$ of blood was drawn and centrifuged and serum (500 microml) collected from that and incubated with the reagent (separate for T3, T4 and TSH) for about 1 hour at room temperature. Later the readings were taken from the instrument COBAS 6000 . The baseline readings were Serum TSH $-0.34-4.25 \mathrm{mIU} / \mathrm{L}$, Serum $\mathrm{T}_{3}-77-135 \mathrm{ng} / \mathrm{dL}$, Serum $\mathrm{T}_{4}-5.4-11.7 \mu \mathrm{g} / \mathrm{dL}$, Free $\mathrm{T}_{3}-0.24-0.42 \mathrm{ng} / \mathrm{dL}$, Free $\mathrm{T}_{4}-0.7-2-1.24 \mathrm{ng} / \mathrm{dL}$.

\section{Statistical Analysis}

Descriptive statistics were presented as mean \pm standard deviation for continuous measures, while absolute values and percentages for categorical measures. All analyses were conducted using the Statistical Package for the Social Sciences (SPSS) 16 statistical software (SPSS Inc., Chicago, Illinois, USA). A p $<0.05$ was considered to be statistically significant throughout the analysis. The difference between different parameters based on quantitative variables are compared using student's t-test for independent samples and the difference is considered statistically significant when the $\mathrm{p}<$ 0.05 .

\section{RESULTS}

In this study, we have found 48 patients with thyroid disorders that is $32 \%$, and out of the 48 patients with thyroid dysfunction 16 (10.67\%) had hypothyroidism, 24 (16.00\%) had subclinical hypothyroidism, 3 (2.00\%) had hyperthyroidism and 5 (3.33\%) had subclinical hyperthyroidism.

The prevalence of thyroid disorders was more in female (44\%) than male $(20 \%)$ and prevalence of hypothyroidism was higher among females (13.33\%) than males (8\%). Hypothyroidism as well as sub-clinical hypothyroidism were more common among elderly females, $15.63 \%$ and $28.13 \%$ respectively.

In this study, prevalence of hypothyroidism (15.52\%) was more in elderly as compared to (7.61\%) adult and middle age group. Diabetes mellitus and thyroid disorders both are common in the elderly. The hypothyroid patients had statistically significant ( $\mathrm{p}$ value: 0.0116 ) higher mean age 64.75 (SD \pm 14.98 ) years as compared to euthyroid patients 56.20 (SD \pm 11.96 ) years.

We have found that there is variation in the TSH levels and T3, T4 levels found in diabetics and diabetics with thyroid disorders. Patients with thyroid disorders had higher levels of TSH as compared to those without thyroid disorders, which was statistically significant $(\mathrm{p}<0.0001)$.

\begin{tabular}{|c|c|c|c|c|c|c|c|}
\hline Sex & Hypothyroidism & $\begin{array}{c}\text { Sub-Clinical } \\
\text { Hypothyroidism }\end{array}$ & Hyperthyroidism & $\begin{array}{c}\text { Sub-Clinical } \\
\text { Hyperthyroidism }\end{array}$ & Normal & Total & P value \\
\hline Male & 6 & 7 & 1 & 1 & 60 & 75 & 0.0027 \\
\hline Female & 10 & 17 & 2 & 4 & 42 & 75 & 0.27 \\
\hline \multicolumn{2}{|r|}{ Table 1. Sex distribution of Thyroid Dysfunction among Diabetic Patients } \\
\hline
\end{tabular}

\begin{tabular}{|c|c|c|c|c|c|c|c|}
\hline Parameter & \multicolumn{2}{|c|}{ DM without Thyroid Dysfunction } & \multicolumn{2}{c|}{ DM with Thyroid Dysfunction } & \multirow{2}{*}{ P value } \\
\hline & Mean & SD & No. of Pts. & Mean & SD & No. of Pts. & 0.4351 \\
\hline T3 & 86.72 & 23.53 & 102 & 83.18 & 30.22 & 48 & 0.0733 \\
\hline T4 & 7.88 & 1.46 & 102 & 7.20 & 3.23 & 48 & $<0.0001$ \\
\hline TSH & 1.87 & 0.96 & 102 & 8.93 & 8.06 & 48 & \\
\hline \multicolumn{7}{|c|}{ Table 2. Distribution according to Thyroid Function Test with Thyroid } \\
Disorders and without Thyroid Disorders among Diabetics
\end{tabular}

All the patients with hypothyroidism had good glycaemic control (mean $\mathrm{HbA}_{1 \mathrm{c}} 7.92$ and $\mathrm{SD} \pm 1.70$ ) compared to euthyroid (mean $\mathrm{HbA}_{1 \mathrm{c}} 8.62$ and SD \pm 1.87 ) and had more chances of hypoglycaemia, while patients with 
hyperthyroidism had poor glycaemic control compared to hypothyroidism.

Hypothyroid patients had a higher mean BMI of 26.78 with SD \pm 3.22 as compared to euthyroid diabetic patients had a mean BMI of 24.17 with SD \pm 2.27 , which was statistically significant ( $\mathrm{p}$ value 0.0001 ).

\begin{tabular}{|c|c|c|c|c|c|}
\hline Duration of DM & No. of Pts. & $\begin{array}{c}\text { DM without Thyroid } \\
\text { Dysfunction }\end{array}$ & $\begin{array}{c}\text { DM with Thyroid } \\
\text { Dysfunction }\end{array}$ & P value \\
\hline $0-5$ yrs. & 59 & 49 & 10 & $16.95 \%$ & 0.0055 \\
\hline $6-10$ yrs. & 74 & 44 & 30 & $40.54 \%$ & $47.06 \%$ \\
\hline > 10 yrs. & 17 & 9 & 8 & $\begin{array}{c}\text { M among Patients with Thyroid Dysfunction and without Thyroid } \\
\text { Dysfunction }\end{array}$ \\
\hline \multicolumn{7}{|c|}{ Table 3. Distribution according to Duration of } \\
\hline
\end{tabular}

\begin{tabular}{|c|c|c|c|c|c|c|c|}
\hline \multirow{2}{*}{ Variables } & DM Patients with Hypothyroidism & \multicolumn{2}{|c|}{ DM Euthyroid Patients } & No. \\
\cline { 2 - 7 } & Mean & SD & Mean & SD & No. of Pts. & P value \\
\hline Age & 64.75 & 14.98 & 16 & 56.20 & 11.96 & 102 & 0.0116 \\
\hline FBS (mg \%) & 166.87 & 53.50 & 16 & 172.68 & 50.55 & 102 & 0.6722 \\
\hline PPBS (mg \%) & 246.75 & 78.51 & 16 & 262.55 & 74.32 & 102 & 0.4342 \\
\hline HbA 1c & 7.92 & 1.70 & 16 & 8.62 & 1.87 & 102 & 0.1618 \\
\hline Mean Duration of DM & 8.37 & 3.38 & 16 & 5.77 & 3.25 & 102 & 0.0037 \\
\hline Serum Total Cholesterol & 217.18 & 37.52 & 16 & 187.83 & 43.59 & 102 & 0.0122 \\
\hline Serum TG & 208.06 & 59.65 & 16 & 166.21 & 76.99 & 102 & 0.0401 \\
\hline Serum LDL & 117.79 & 16.94 & 16 & 98.32 & 27.18 & 102 & 0.0064 \\
\hline HDL & 37.90 & 5.31 & 16 & 46.05 & 7.29 & 102 & 0.0001 \\
\hline Non-HDL Cholesterol & 179.28 & 37.60 & 16 & 141.77 & 44.31 & 102 & 0.0017 \\
\hline BMI & 26.78 & 3.22 & 16 & 24.17 & 2.27 & 102 & 0.0001 \\
\hline Waist-Hip Ratio (Male) & 1.22 & 0.10 & 6 & 1.10 & 0.09 & 60 & 0.0030 \\
\hline Waist-Hip Ratio (Female) & 1.08 & 0.14 & 10 & 0.95 & 0.08 & 42 & 0.0003 \\
\hline
\end{tabular}

\section{DISCUSSION}

In this study we have found 48 patients with thyroid disorders that is $32 \%$ and out of 48 patients with thyroid dysfunction 16 (10.67\%) had hypothyroidism, $24(16.00 \%)$ had subclinical hypothyroidism, 3 (2.00\%) had hyperthyroidism and 5 (3.33\%) had subclinical hyperthyroidism.

\begin{tabular}{|c|c|c|c|}
\hline Studies & $\begin{array}{l}\text { Prevalence of Thyroid } \\
\text { Dysfunction in DM }\end{array}$ & $\begin{array}{c}\text { Total } \\
\text { Hypothyroidism } \\
\end{array}$ & $\begin{array}{c}\text { Overt } \\
\text { Hypothyroidism } \\
\end{array}$ \\
\hline Pasupathi et al (2008) & $45 \%$ & $28.00 \%$ & --- \\
\hline Celani MF et al (1994)10 & $31.4 \%$ & $22.41 \%$ & $7.24 \%$ \\
\hline Diez J J et al (2011) ${ }^{11}$ & $32.40 \%$ & $25.8 \%$ & $15.10 \%$ \\
\hline Demitrost et al (2012) ${ }^{12}$ & $31.20 \%$ & $27.7 \%$ & $11.40 \%$ \\
\hline Present Study & $32 \%$ & $26.67 \%$ & $10.67 \%$ \\
\hline
\end{tabular}

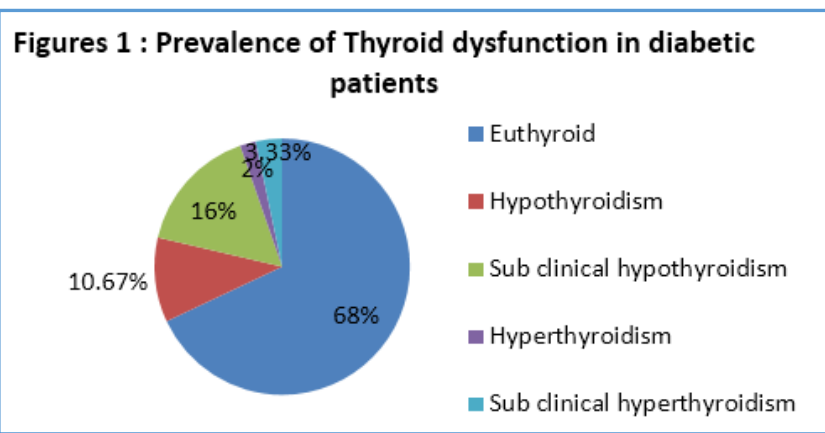

This study was similar to Diez J J et al (2011) ${ }^{11}$ among type $2 \mathrm{DM}$ patients in Spain that found that prevalence of thyroid dysfunction was $32.40 \%$ and a retrospective study by Demitrost $^{12}$ et al (2012) shows the prevalence of thyroid disorders 32\%, subclinical hypothyroidism and hypothyroidism cases $(16.00 \%$ versus $16.3 \%$ and $10.67 \%$ versus $11.4 \%$, respectively).
In this study, prevalence of hypothyroidism (15.52\%) was more in elderly as compared to (7.61\%) adult and middle age group. Diabetes mellitus and thyroid disorders both are common in the elderly.

The hypothyroidism patients had statistically significant ( $p$ value: 0.0116 ), higher mean age 64.75 (SD \pm 14.98 ) years as compared to euthyroid patients 56.20 (SD \pm 11.96 ) years. These finding are similar to study by Kim et al (2011). ${ }^{13}$ Mean age of Euthyroid patients of type 2 DM was 57.8 (SD \pm 11.8 ) years and the mean age of type 2 diabetics with SCH was 61.7 ( $\mathrm{SD} \pm 9.8$ ) years ( $\mathrm{p}$ value: 0.014 ) indicating that $\mathrm{SCH}$ in type 2 DM was associated with increasing age. In the study by Unnikrishnan AG et al (2013),14 prevalence of hypothyroidism was the highest in the age group of 46 to 54 years $(13.11 \%)$ and the lowest in that of 18 to 35 years (7.53\%).

The prevalence of thyroid disorders was more in female (44\%) than male $(20 \%)$ and prevalence of hypothyroidism was higher among females (13.33\%) than males $(8 \%)$. 
Hypothyroidism as well as sub-clinical hypothyroidism were more common among elderly females $15.63 \%$ and $28.13 \%$ respectively. This study is similar to Ambika Gopalakrishnan et al (2013) ${ }^{15}$ that shows larger proportion of females than males $(15.86 \%$ vs. $5.02 \%$; $<$ 0.0001) who were found to be affected by hypothyroidism.

We have found that patients with thyroid disorders had higher levels of TSH as compared to those without thyroid disorders, which was statistically significant $(\mathrm{p}<0.0001)$. There was not statistically significant difference noted in T4 and T3 levels. Findings in our study are similar to that of Pasupathi et al (2008) ${ }^{16}$ and Shalini Gupta et al (2011).17

In our study, increased duration of diabetes had significant relation to hypothyroidism in this study $(\mathrm{p}=$ 0.0037). These observations are similar to study by R. Anil Kumar et al (2013),18 the reported study in which they had subclinical hypothyroidism and overt hypothyroidism appear to be significantly associated with duration of diabetes, 11.48 \pm 7.96 years and $8.76 \pm 7.23$ years respectively vs. $7.91 \pm 7.07$ years in euthyroid diabetes patients $(p=0.019)$. Saroj Khatiwada et al $(2015)^{19}$ reported that age $\geq 60$ years and duration of diabetes $\geq 5$ years had relative risk of thyroid dysfunction.

In this study, we have found that out of 150 patients with diabetes, symptoms of thyroid disorder were present in 24 patients. Among the 16 hypothyroid patients detected in the study, 10 (62.5\%) patients had sign and symptoms suggestive of hypothyroidism. Diabetic patients commonly display the signs and symptoms of hypothyroidism and similar result reported by Udiong et al (2007).20

Thyroid dysfunction are associated with more diabetic complications as compared to euthyroid patients in the form of retinopathy, nephropathy and neuropathy based on clinical and laboratory evidences (43.42\% v/s $20.27 \%)$. Yang et al $(2010)^{21}$ showing that SCH was associated with sightthreatening diabetic retinopathy, but differed from those of Chen et al (2007) 22 who reported an association between SCH and an increased risk of nephropathy, but not with retinopathy.

We found that all the patients with hypothyroidism had good glycaemic control (mean $\mathrm{HbA}_{1 \mathrm{c}} 7.92$ and $\mathrm{SD} \pm 1.70$ ) compared to euthyroid (mean $\mathrm{HbA}_{1 \mathrm{c}} 8.62$ and $\mathrm{SD} \pm 1.87$ ) and had more chances of hypoglycaemia, while patients with hyperthyroidism had poor glycaemic control compared to hypothyroidism. Our results are similar to the study by Manjunath SC et al (2013) ${ }^{23}$ studies, in which among the 13 SCH patients they found the similar findings. This could be due to the effect of thyroid hormone on insulin.

In the present study among hypothyroid patients, the mean values of serum TC, LDL, TG and non-HDL cholesterol were relatively higher than the respective mean values in euthyroid subjects, whereas mean serum HDL was relatively lower in hypothyroid patients than euthyroid subjects which was statistically significant. In a study conducted by Chubb SAP et al (2005), ${ }^{24}$ SCH patients had significantly higher serum TC than euthyroid subjects (mean \pm SD $243.62 \pm 50.27$ $\mathrm{mg} \%$ vs. $224.28 \pm 46.4 \mathrm{mg} \%, \mathrm{p}$ value $<0.001)$ and significantly higher serum LDL than euthyroid subjects (mean \pm SD $166.27 \pm 50.27 \mathrm{mg} \%$ vs. $135.34 \pm 38.67 \mathrm{mg} \%$, p value < 0.001). Saroj Khatiwada et al (2015) ${ }^{19}$ in their study reported that diabetic patients with thyroid dysfunction had higher total cholesterol, HDL cholesterol and LDL cholesterol in comparison to patients without thyroid dysfunction.

Hypothyroid patients had a higher mean BMI of 26.78 with SD \pm 3.22 as compared to euthyroid diabetic patients had a mean BMI of 24.17 with $\mathrm{SD} \pm 2.27$, which was statistically significant ( $p$ value 0.0001 ). Demitrost $L$ et al $(2012)^{12}$ reported that patients with BMI > 25 were at increased risk of having thyroid dysfunction ( $p<0.016$ ). Kumar R A et al (2013) ${ }^{18}$ reported higher mean BMI of hypothyroid patients $27.65 \pm 4.34$ as compared to euthyroid diabetic patients $26.62 \pm 4.16$. The waist-hip ratio was higher in hypothyroid patients as compared to euthyroid patients which was statistically significant.

\section{SUMMARY AND CONCLUSION}

Prevalence of thyroid dysfunction was 32\% in diabetic patients. Most common dysfunction was sub-clinical hypothyroidism $(16 \%)$ followed by overt hypothyroidism (10.67\%), subclinical hyperthyroid (3.33\%) and hyperthyroid (2\%). Prevalence of hypothyroidism (15.51\%) was more in elderly (mean age- $64.75 \pm 14.98$ yrs.). Thyroid disorders are more in females (44\%) than males $(20 \%)$. Increased duration of diabetes was associated with more chances of thyroid dysfunction. Hypothyroid patients had statistically significant higher BMI and mean waist-hip ratio as compared to euthyroid diabetics. Hyperthyroidism patients had poor glycaemic control and hypothyroid patients had more chances of hypoglycaemia.

We conclude that screening for thyroid disease among diabetic patients should be routinely performed considering the prevalence of new cases diagnosed and the possible aggravation of the classical risk factors such as hypertension and dyslipidaemia arising from an undiagnosed thyroid dysfunction. Furthermore, it seems that unidentified thyroid dysfunction could negatively impact diabetes and its complications. Therefore, we recommended that every diabetic patient should undergo thyroid profile, so early detection and management of hypothyroidism in patients with diabetes may prove beneficial.

\section{REFERENCES}

[1] Fauci AS, Braunwald E, Kasper DL, et al. Harrison's principles of internal medicine. $18^{\text {th }}$ edn. USA: McGraw-Hill 2008.

[2] Wild S, Roglic G, Green A, et al. Global prevalence of diabetes: estimates for the year 2000 and projections for 2030. Diabetes Care 2004;27(5):1047-53.

[3] Satish R, Mohan V. Diabetes and thyroid diseasesreview. Int J Diab Dev Countries 2003;23(4):120-3.

[4] Patricia WU. Thyroid diseases and diabetes. Clinical Diabetes winter 2000;18(1).

[5] Fernandez-Real JM, Lopez-Bermejo A, Castro A, et al. Thyroid function is intrinsically linked to insulin sensitivity and endothelium-dependent vasodilation in healthy euthyroid subjects. J Clin Endocrinol Metab 2006;91(9):3337-43.

[6] Raboudi N, Arem R, Jones RH, et al. Fasting and postabsorptive hepatic glucose and insulin metabolism in hyperthyroidism. Am J Physiol 1989;256(1Pt 1):E159-66. 
[7] Weinstein SP, O'Boyle E, Fisher M, et al. Regulation of GLUT2 glucose transporter expression in liver by thyroid hormone: evidence for hormonal regulation of the hepatic glucose transport system. Endocrinology 1994;135(2):649-54.

[8] Clement $K$, Viguerie $N$, Diehn $M$, et al. In vivo regulation of human skeletal muscle gene expression by thyroid hormone. Genome Res 2002;12(2):281-91.

[9] Viguerie N, Millet L, Avizou S, et al. Regulation of human adipocyte gene expression by thyroid hormone. J Clin Endocrinol Metab 2002;87(2):630-4.

[10] Celani MF, Bonati ME, Stucci N. Prevalence of abnormal thyrotropin concentrations measured by a sensitive assay in patients with type 2 diabetes mellitus. Diabetes Res 1994;27(1):15-25.

[11] Díez JJ, Sánchez P, Iglesias P. Prevalence of thyroid dysfunction in patients with type 2 diabetes. Exp Clin Endocrinol Diabetes 2011;119(4):201-7.

[12] Demitrost L, Ranabir S. Thyroid dysfunction in type 2 diabetes mellitus: a retrospective study. Indian J Endocrinol Metab 2012;16(Suppl 2):S334-5.

[13] Kim BY, Kim CH, Jung CH, et al. Association between subclinical hypothyroidism and severe diabetic retinopathy in Korean patients with type 2 diabetes. Endocr J 2011;58(12):1065-70.

[14] Unnikrishnan AG, Kalra S, Sahay RK, et al. Prevalence of hypothyroidism in adults: an epidemiological study in eight cities of India. Indian J Endocr Metab 2013;17(4):647-52.

[15] Papazafiropoulou A, Sotiropoulos A, Kokolaki A, et al. Prevalence of thyroid dysfunction among Greek type 2 diabetic patients attending an outpatient clinic. Journal of Clinical Medicine Research 2010;2(2):75-8.
[16] Pasupathi P, Bakthavathsalam G, Saravanan G, et al. Screening for thyroid dysfunction in the diabetic/nondiabetic population. Thyroid Science 2008;3(8):CLS16.

[17] Gupta S, Verma M, Gupta AK, et al. Are we using thyroid function tests appropriately? Ind J Clin Biochem 2011;26(2):178-81.

[18] Kumar RA, Narasimhasetty KR, Lalitha R, et al. Prevalence of thyroid dysfunction among type 2 diabetes subjects in South India. International Journal of Clinical Cases and Investigations 2013;5(6):93-100.

[19] Khatiwada S, Rajendra KC, Sah SK, et al. Thyroid dysfunction and associated risk factors among nepalese diabetes mellitus patients. Int J Endocrinol 2015;2015:5.

[20] Udiong CEJ, Udoh AE, Etukudoh ME. Evaluation of thyroid function in diabetes mellitus in Calabar, Nigeria. Indian Journal of Clinical Biochemistry 2007;22(2):74-8.

[21] Yang JK, Liu W, Shi J, et al. An association between subclinical hypothyroidism and sight-threatening diabetic retinopathy in type 2 diabetic patients. Diabetes Care 2010;33(5):1018-20.

[22] Chen HS, Wu TE, Jap TS, et al. Subclinical hypothyroidism is a risk factor for nephropathy and cardiovascular diseases in type 2 diabetic patients. Diabet Med 2007;24(12):1336-44.

[23] Manjunath SC, Krishnamurthy V, Puttaswamy BK, et al. Prevalence of subclinical thyroid disorders in type 2 diabetes mellitus. Int J Med Public Health 2013;3:330 4.

[24] Chubb SAP, Davis WA, Inman Z, et al. Prevalence and progression of subclinical hypothyroidism in women with type 2 diabetes: the fremantle diabetes study. Clin Endocrinol 2005;62(4):480-6. 